\title{
Relative outflow enhancements during major geomagnetic storms - Cluster observations
}

\author{
Audrey Schillings ${ }^{1,2}$, Hans Nilsson ${ }^{1,2}$, Rikard Slapak ${ }^{2}$, Masatoshi Yamauchi ${ }^{1}$, and Lars-Göran Westerberg ${ }^{3}$ \\ ${ }^{1}$ Swedish Institute of Space Physics, Kiruna, Sweden \\ ${ }^{2}$ Division of Space Technology, Luleå University of Technology, Kiruna, Sweden \\ ${ }^{3}$ Division of Fluid and Experimental Mechanics, Luleå University of Technology, Luleå, Sweden
}

Correspondence: Audrey Schillings (audrey.schillings@irf.se)

Received: 6 April 2017 - Revised: 26 October 2017 - Accepted: 2 November 2017 - Published: 15 December 2017

\begin{abstract}
The rate of ion outflow from the polar ionosphere is known to vary by orders of magnitude, depending on the geomagnetic activity. However, the upper limit of the outflow rate during the largest geomagnetic storms is not well constrained due to poor spatial coverage during storm events. In this paper, we analyse six major geomagnetic storms between 2001 and 2004 using Cluster data. The six major storms fulfil the criteria of Dst $<-100 \mathrm{nT}$ or $\mathrm{Kp}>7+$. Since the shape of the magnetospheric regions (plasma mantle, lobe and inner magnetosphere) are distorted during large magnetic storms, we use both plasma beta $(\beta)$ and ion characteristics to define a spatial box where the upward $\mathrm{O}^{+}$flux scaled to an ionospheric reference altitude for the extreme event is observed. The relative enhancement of the scaled outflow in the spatial boxes as compared to the data from the full year when the storm occurred is estimated. Only $\mathrm{O}^{+}$ data were used because $\mathrm{H}^{+}$may have a solar wind origin. The storm time data for most cases showed up as a clearly distinguishable separate peak in the distribution toward the largest fluxes observed. The relative enhancement in the outflow region during storm time is 1 to 2 orders of magnitude higher compared to less disturbed time. The largest relative scaled outflow enhancement is 83 (7 November 2004) and the highest scaled $\mathrm{O}^{+}$outflow observed is $2 \times 10^{14} \mathrm{~m}^{-2} \mathrm{~s}^{-1}$ (29 October 2003).
\end{abstract}

Keywords. Magnetospheric physics (storms and substorms; magnetosphere-ionosphere interactions; solar-windmagnetosphere interactions)

\section{Introduction}

The young sun appears to have been much more active; flares were more frequent and the solar wind was more powerful and had stronger high-energy emissions (Ribas et al., 2005). Thus, current geomagnetic storms can be considered as a proxy for the normal conditions of the past (Krauss et al., 2012). Therefore, studies of outflow for extreme events have implications outside direct space weather effects. Indeed, the ion outflow under current major geomagnetic storms could have been the normal rate of ion outflow in the past (young sun), so ion outflow during storms may be especially important to understand atmospheric evolution on a geological timescale. Slapak et al. (2017) roughly estimated the escape rate in the past. The authors extrapolated their result on the $\mathrm{O}^{+}$escape rate in the plasma mantle and dayside magnetosheath to the past and obtained a total $\mathrm{O}^{+}$loss of about $40 \%$ of today's total oxygen mass in the atmosphere. Ion outflow and escape from the polar ionosphere play a key role in magnetospheric dynamics and atmospherical evolution and have been the subject of numerous studies; see, e.g., Kronberg et al. (2014) and references therein. However, there is a lack of studies on escaping ions during extreme geomagnetic conditions. This study presents observations of outflowing ions during major geomagnetic storms and discusses them in terms of relative enhancements because there is not enough data to fully quantify the escape.

The regions of open magnetic field lines, which include the cusp, the polar cap and the plasma mantle, are the main pathways for ion outflow leading to escape (Nilsson et al., 2012). The cusp is the dayside region of recently opened magnetic field lines where the solar wind has the most direct entry to the magnetosphere. The plasma mantle is the high- 
altitude region downstream of the cusp, dominated by solar wind ions that have been reflected by the mirror force of the earth's magnetic field, streaming outward and tailward. The polar cap is the whole region of open magnetic field lines mapping mainly to the magnetotail lobes. Ion outflow occurs from all of these regions, but the oxygen outflow from the cusp and mantle is most intense and also most likely to escape into interplanetary space (Nilsson et al., 2012; Slapak et al., 2013).

A dependency on magnetospheric conditions and interplanetary magnetic field (IMF) has been established for outflowing ions in the altitude range of 1.3 to $2.0 R_{\mathrm{E}}$ (Yau et al., 1988). Yau et al. (1988) showed that upflow increase exponentially with geomagnetic activity as measured by the Kp index. A Kp increased from 0 to 6 led to a factor of 20 increase in $\mathrm{O}^{+}$outflow and a factor of 4 increase in $\mathrm{H}^{+}$outflow in their covered energy range of 0.01 to $17 \mathrm{keV}$. What the fate of these outflowing ions will be and where they will end up is not clear because of the relatively low altitude of these observations. Slapak et al. (2017) carried out a similar study of Kp dependence based on high-altitude Cluster spacecraft data, trying to estimate the total atmospheric escape by looking at the plasma mantle and the magnetosheath. The authors estimate the contribution from the plasma mantle as $3.9 \times 10^{24} \exp (0.45 \mathrm{Kp}) \mathrm{s}^{-1}$. They could not obtain a direct escape estimation for the most extreme geomagnetic conditions because of a lack of statistics.

Their study only concerned $\mathrm{O}^{+}$, as it is more challenging to distinguish the ionospheric origin of $\mathrm{H}^{+}$from solar wind in the plasma mantle. The same is true of our study, and we will therefore only discuss $\mathrm{O}^{+}$outflow.

During geomagnetic storms, the solar wind speed and density are higher than usual. The solar wind is mainly composed of $\mathrm{H}^{+}$and thus most of the oxygen ions observed in the magnetosphere originate from the ionosphere (Shelley et al., 1982; Chappell et al., 1987). As discussed above, the outflow of both $\mathrm{O}^{+}$and $\mathrm{H}^{+}$increases with geomagnetic activity.

Kistler et al. (2010) showed that the density of the oxygen ions in the cusp increases by a factor of 10 before or during the early main phase of a storm. This result was corroborated by Liao et al. (2010), who found that the occurrence frequency of $\mathrm{O}^{+}$observations in the lobes increases during the storm main phase. Liao et al. (2015) discussed the influence of the geomagnetic activity on the velocity increase in $\mathrm{O}^{+}$as it is transported from the cusp to the tail lobe. The authors found that from the cusp to the polar cap and to the tail lobes, the acceleration of oxygen ions is not significant. However, during storm time, accelerated $\mathrm{O}^{+}$was observed in the cusp. Nilsson et al. (2012) showed consistent results with a little acceleration in the polar cap and lobes but significant heating and subsequent acceleration in the cusp and plasma mantle. They did however not divide their data according to geomagnetic activity.

Plasma in the tail lobes typically ends up in the plasma sheet. An enhancement of the oxygen ions density and pres- sure in the plasma sheet has been observed for disturbed geomagnetic conditions (Kistler et al., 2006, 2010). Li et al. (2012) investigated the sources for magnetospheric cold ions and the change in the outflow rate during geomagnetic disturbances (Dst $<-20 \mathrm{nT}$ ). They found that cold-ion outflow was higher during disturbed magnetospheric conditions, consistent with the findings of Haaland et al. (2012). They also showed that the polar cap area is extended for disturbed times. These studies show how outflow is increased and also show the transport to the plasma sheet. The question is how much of these flowing ions will escape into interplanetary space during geomagnetic storms. Haaland et al. (2015) studied the cold ions during two geomagnetic storms. The authors calculated the characteristic outflow parameters, and they found that the density and bulk outflow velocity vary with the storm intensity. They estimated the cold-ion outflow rate to vary by 1 order of magnitude between disturbed and quiet magnetospheric conditions.

Without taking geomagnetic activity into account, the amount of escaping ions has been discussed in a number of studies. Seki et al. (2001) discussed outflow and return flow in the plasma sheet. They observed less and less $\mathrm{O}^{+}$outflow with tail distance, covering distances from 0 to $210 R_{\mathrm{E}}$ and suggested that this was because of transport to the plasma sheet. The authors mentioned two transport processes leading to ion escape through the plasma sheet: a plasmoid that is formed by a tailward injection of a helical magnetic field structure and the transport of ions coming from the lobe or plasma mantle region to the distant neutral line. Other studies have shown that ion heating and acceleration in the cusp and mantle instead lead to escape into the magnetosheath for these ions (Nilsson et al., 2006, 2012; Nilsson, 2011; Slapak et al., 2013). A statistical study on $\mathrm{O}^{+}$flux from Slapak et al. (2013) estimated the total escape flux observed in the dayside magnetosheath to be $\sim 7 \times 10^{24} \mathrm{~s}^{-1}$. Nilsson (2011) similarly estimated the escaping flux in the cusp and plasma mantle to be of the order of $10^{25} \mathrm{~s}^{-1}$. Low-energy ions which flow out from the polar cap are called polar wind and were first discussed by Axford (1968). Moore et al. (1997) studied polar wind at high altitude, and, with POLAR spacecraft, they observed the acceleration of the polar wind through the lobes supplying the plasma sheet. They also found that supersonic ionospheric outflow travelling along the local magnetic field lines fills the lobe region, which was believed to be empty of plasma. Studies by Engwall et al. (2006) and Haaland et al. (2012) studied cold plasma and found that around $10^{25}$ ions s $^{-1}$ of the outflowing cold ions are lost to the solar wind. A study by Nilsson et al. (2010) indicated that these cold ions are made up of protons and not oxygen. Moreover, geomagnetic disturbances lead to significant enhancement of the outflow but also strong convection towards the plasma sheet (Haaland et al., 2012, 2015).

This paper studies the relative outflow enhancement of $\mathrm{O}^{+}$ for six case studies of major geomagnetic storms between 2001 and 2004. In Sect. 2, a brief description of the Clus- 
ter mission and the instruments used is given. Section 3 describes the methodology and how the data set was chosen. Thereafter, the observations on the oxygen ion outflow during the six storms are presented in Sect. 4. Finally, in Sects. 5 and 6 , we discuss the results and summarize the paper.

\section{Instrument and data analysis}

The Cluster mission (Escoubet et al., 2001) consists of four identical spacecraft flying in tetrahedral formation in an elliptical polar orbit. In this study, data from the Cluster Ion Spectrometer (CIS) instrument are used. The COmposition DIstribution Function (CODIF) is part of the CIS instrument and uses a time-of-flight technique that enables us to distinguish between $\mathrm{H}^{+}, \mathrm{He}^{2+}, \mathrm{He}^{+}$and $\mathrm{O}^{+}$in terms of mass per charge (see Rème et al., 2001). During major events, intense $\mathrm{H}^{+}$fluxes may contaminate other mass channels. To remove such data, a method described by Nilsson et al. (2006) is applied. Finally, the fluxgate magnetometer (FGM) provides the magnetic field data (see Balogh et al., 2001).

\section{Data set and methodology}

The data set consists of Cluster data from 2001 to 2004 . During these years, several geomagnetic storms occurred, of which six were major geomagnetic storms. Our major geomagnetic storms are defined by Dst $\leq-100 \mathrm{nT}$ or $\mathrm{Kp} \geq 7+$ according to Zhang et al. (2007). Furthermore, the six chosen storms occurred during months which have a higher occurrence rate for geomagnetic storms, namely April-May and October-November (Zhang et al., 2007; Kamide et al., 1998). In the following sections, we define outflow as local flux with a net outward flux. In order to study changes in the outflow from the ionosphere, we use the upward $\mathrm{O}^{+}$flux scaled to an ionospheric altitude to compensate for altitude dependencies and magnetospheric compressions. We will in the following text term this "scaled outflow". The local flux can be mapped to an ionospheric altitude by considering an ionospheric magnetic field strength of $50000 \mathrm{nT}$ and assuming the total flux to be conserved along a magnetic flux tube. For each event, the scaled oxygen ion outflow is investigated and compared to the average scaled outflow during 1 year (the year of the storm). During these events, we do not have data from all the spacecraft and the available data are not necessarily crossing the regions of main ion outflow so that the spatial coverage of the extreme storm events is poor. We try to overcome this by looking at the relative change in the scaled outflow in the region where suitable Cluster observations were made.

Spectrograms and the magnetic fields related to the extreme storms are plotted to define the duration of the event and remove regions of closed magnetic field lines. Spectrograms and magnetic field are investigated for spacecraft 1 (SC1), SC3 and SC4 to identify the spacecraft with the best data set for each storm and see if $\mathrm{O}^{+}$fluxes are visible during the storms (more detail in Sect. 3.1). Once the duration of the event has been determined, we define a spatial region corresponding to the storm event. This spatial region corresponding to the storm event is defined as a box which covers the spacecraft trajectory during the duration of our event. Our observations were made in the high-altitude polar cap and plasma mantle, where the plasma beta $(\beta)$ value, i.e. the ratio of the plasma pressure over the magnetic pressure, varies. Thus, we investigate the plasma beta for our events, as it could represent outflow in different regions within the spatial boxes. The plasma beta in the polar cap is considerably smaller than in the magnetosheath $(\beta \approx 1)$. In addition, inside the magnetosphere, the plasma beta helps to distinguish the cusp and plasma mantle $(\beta>0.1)$ from the polar cap $(\beta<0.1)$ regions. The spatial distribution of the plasma beta in our region of interests is shown and discussed in the next section where we use a sample case to illustrate the method in more details. Therefore, to identify the regions included in our spatial box, for each storm, the plasma beta, $\mathrm{O}^{+}$and $\mathrm{H}^{+}$ fluxes along the trajectory of the selected spacecraft are investigated. In practice the plasma beta during the event was selected to be lower than $\beta<0.1$, as there were very few data from the cusp and plasma mantle region $(\beta>0.1)$. We then check that the plasma beta of the event does not stand out from the plasma beta observed in the same box for all data obtained during the year of the storm. Finally, the scaled oxygen ion outflow in this spatial box is represented in histograms for 1 year of data and for the major storm itself. This is done for each extreme event separately. In the next section, one of the storms, the Halloween event on 29 October 2003, is used to illustrate the steps of the method in more detail.

\subsection{Sample event}

The steps of the method are described in more detail using the 29 October 2003 part of the Halloween storm as an example. The first step of the method is to look at the magnetic field and the energy and pitch-angle spectrograms of $\mathrm{O}^{+}$and $\mathrm{H}^{+}$respectively. Figure 1 shows the spectrograms for the Halloween event on 29 October 2003 between 08:30 and 20:00 UT. Panel (a) shows the magnetic field components. Panels (b) and (c) represent the energy spectrograms for $\mathrm{O}^{+}$ and $\mathrm{H}^{+}$respectively and panels $(\mathbf{d}),(\mathbf{e})\left(\mathrm{O}^{+}\right)$and $(\mathbf{f})\left(\mathrm{H}^{+}\right)$the corresponding pitch-angle distributions for different energy ranges. First, we perform a visual inspection of the energy spectrograms to identify the presence of $\mathrm{O}^{+}$in the open field line region (b). Then, we look at the pitch-angle data for the ion outflow at different energy ranges. We see from panel (d) that the $\mathrm{O}^{+}$pitch angle $(0.3-30 \mathrm{keV})$ is close to $0^{\circ}$ between 08:30 and 11:00 UT and from panel (e) that it is close to $180^{\circ}$ between approximately 15:00 and 20:00 UT (0.03-0.3 keV). Note that part of the apparent $\mathrm{O}^{+}$fluxes seen during the inbound leg are due to the crosstalk from intense fluxes of protons. These periods are not included in our data set. In the po- 
(a)

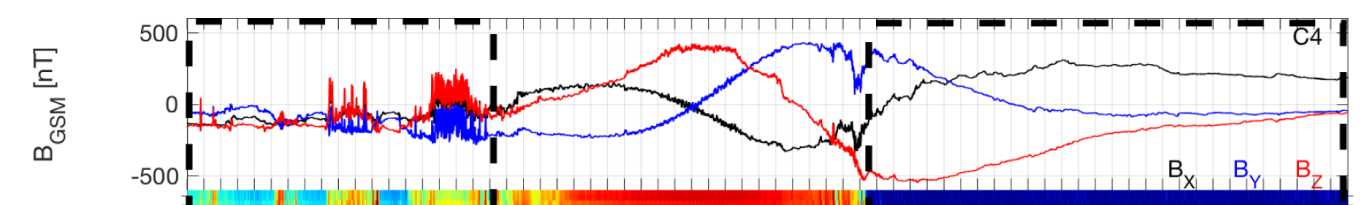

(b)

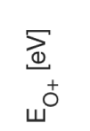

(c)

$\frac{\text { 迹 }}{\text { 山 }^{ \pm}}$

(d)

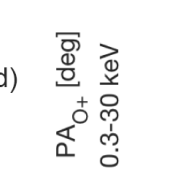

(e)

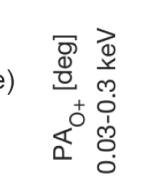

(f)

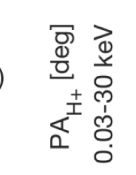
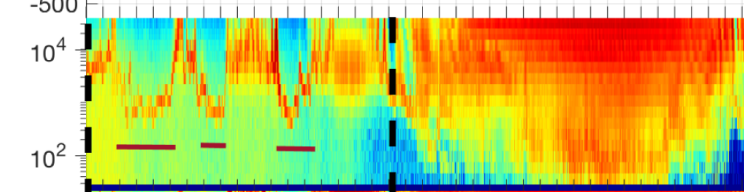

if
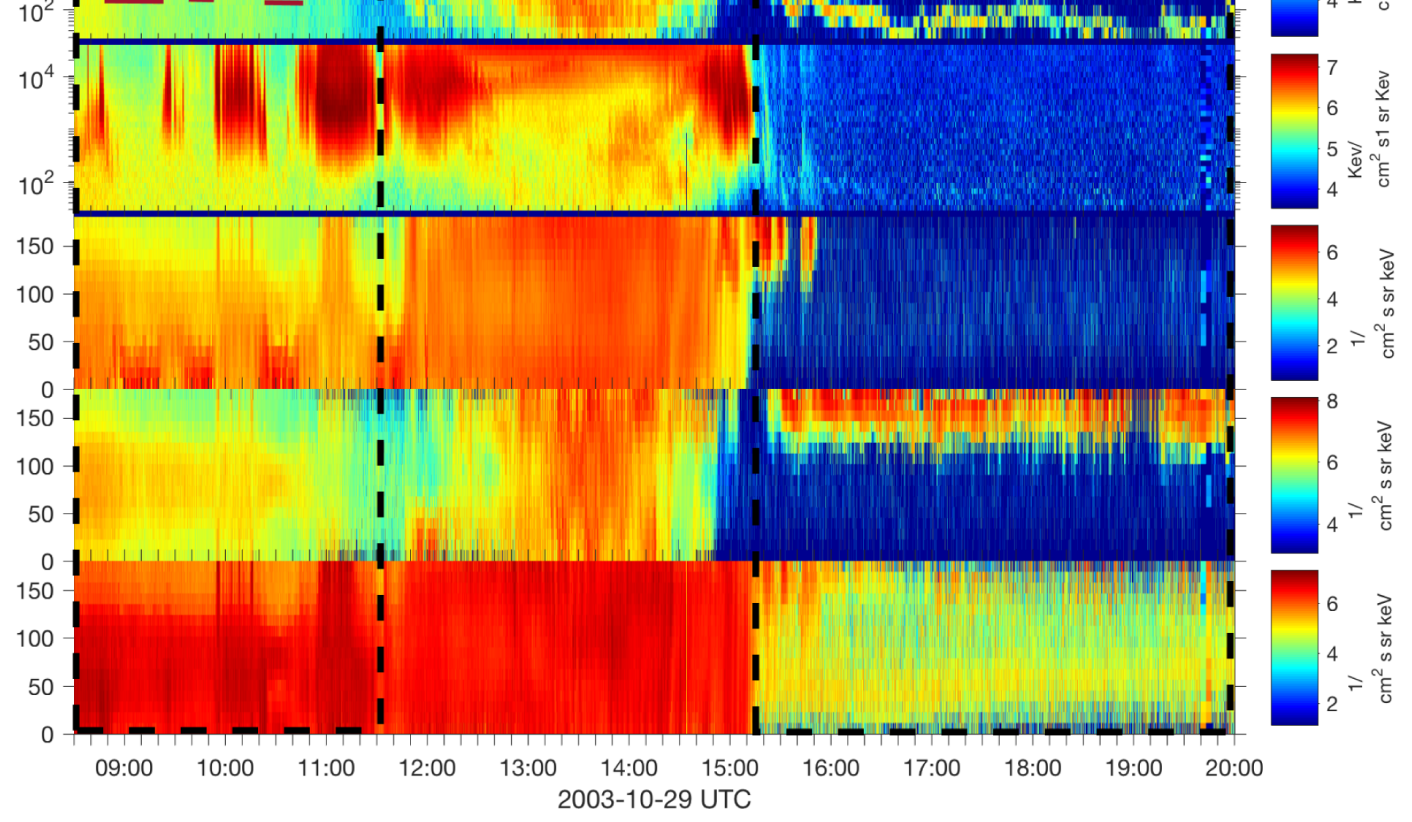

Figure 1. Magnetic field, energy and pitch-angle spectrograms for the Halloween event on 29 October 2003 between 08:30 and 20:00 UT with Cluster SC4. The panel (a) shows the three components of the magnetic field in nT during the storm. Panels (b) and (c) represent the energy spectrogram $(\mathrm{eV})$ for $\mathrm{O}^{+}$and $\mathrm{H}^{+}$respectively. Panels (d), (e) and (f) show the corresponding pitch angle $\left(^{\circ}\right)$ for different energy ranges. The black dashed rectangles show the regions identified as the open magnetic field line regions, and the red lines in the $\mathrm{O}^{+}$energy spectrogram show the regions included in the data (magnetosheath is excluded).

lar cap region, the pitch-angle spectra usually show less variability than in the magnetosheath or within the closed field line region. Moreover, narrow oxygen beams are included as well as a clear high-energy $\mathrm{O}^{+}$outflow that relates to a strong magnetic field (not shown; this does not apply to the Halloween event), for example $B \sim 200 \mathrm{nT}$ for 29-30 May 2003 in the Southern Hemisphere. Finally, to confirm the location of the outflow region; panel (a) shows that the magnetic field slowly varies and stronger in the inner magnetosphere; in the open field line regions, it is weaker and more strongly oscillating in the magnetosheath. The regions of open magnetic field lines (outflow regions) are thus identified between 08:30 and 11:30 UT for the Southern Hemisphere (SH) and between 15:15 and 20:00 UT for the Northern Hemisphere (NH) represented by the black dashed rectangles. To summarize, this identification is based on the pitch-angle data showing field-aligned flow and the presence of $\mathrm{O}^{+}$ions, the magnetic field being weak but quite stable and then also using the location of the spacecraft in the general polar cap-cuspplasma mantle regions. In Fig. 1c, the first dashed black box indicates a region in the $\mathrm{SH}$ where intense fluxes of $\mathrm{H}^{+}$at several kilo-electronvolts energy are observed. We interpret these data as magnetosheath data and the variation between high and low energies in $\mathrm{H}^{+}$as flapping motions of the magnetopause. Such magnetosheath data are removed by our algorithm, which removes $\mathrm{O}^{+}$data significantly contaminated by crosstalk from intense proton fluxes (see Nilsson et al., 2006, for more detail). The periods of data included in our data set are shown with red lines (panel (b)).

Figure 2 shows the second step of the method. As briefly mentioned at the beginning of Sect. 3, the plasma beta is used to distinguish between the different magnetospheric regions. Therefore, the plasma beta and the oxygen ion flux is computed along the entire spacecraft trajectory during the event. Fig. 2a shows the plasma beta along Cluster SC4 trajectory in the $\mathrm{XZ}_{\mathrm{GSM}}$ and $\mathrm{XY}_{\mathrm{GSM}}$ planes respectively. Fig. 2b shows the corresponding oxygen ion flux. The colour scales represent the logarithmic values of the plasma beta and the oxygen ion flux respectively. Black arrows illustrate the direction of the spacecraft motion, starting at 08:30 and ending 
29-Oct-2003 (sc4) (a)
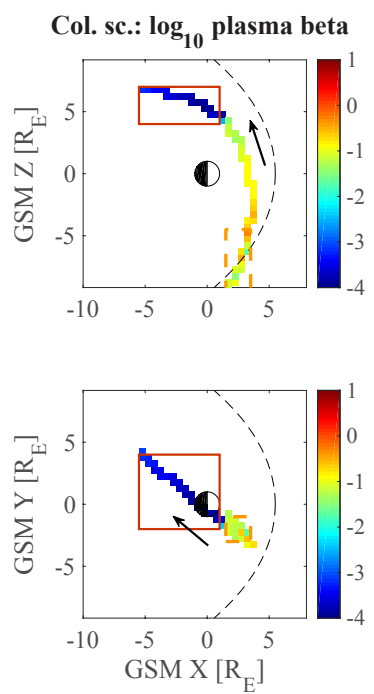

(b)
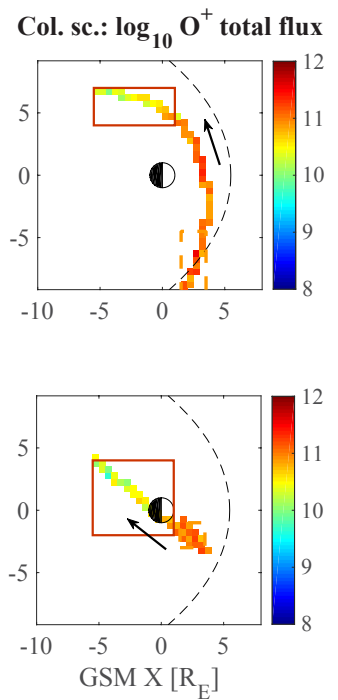

Figure 2. The plasma beta (a) and the $\mathrm{O}^{+}$flux (b) along the trajectory of Cluster SC4 on 29 October 2003 from 08:30 to 20:00 UT. The location of the magnetopause is a prediction obtained from the model of Shue et al. (1998) for the solar wind conditions at around 11:00 UT.

at 20:00 UT. In addition, the magnetopause is represented by a dashed black line in all panels and is a prediction obtained from the model of Shue et al. (1998) for the solar conditions at around 11:00 UT. The entry and exit time (08:30 and 11:30 UT for the SH and 15:15 and 20:00 UT for the $\mathrm{NH}$, defined in Fig. 1) in the region of interest is converted to spacecraft positions in geocentric solar magnetospheric (GSM) coordinates. These positions are plotted and give a spatial box for the region of outflow during the event. Then, we inspect whether the spatial box defined by the positions converted from the entry and exit time (Fig. 1) corresponds to plasma beta lower than 0.1 in Fig. 2. The final spatial box is sometimes slightly adjusted to give a plasma beta within the range $<0.1$ along the trajectory. The spatial boxes for the Halloween event obtained in this way are illustrated by red and orange rectangles for the NH and SH respectively.

The third step is to perform statistics over 1 year of data in the spatial boxes defined by the storm. First, we check that, in terms of plasma beta, the geomagnetic storm does not stand out from the average for the year for the spatial region and that the plasma beta is in the same range (less than 0.1) in our spatial box during the year. Figure 3 illustrates the average distribution of $\beta$ in cylindrical coordinates for 2003, storms included, and for the regions of the magnetosphere that we investigate in this study. The cylindrical coordinates are used so that Fig. 3 can be directly compared to that of Nilsson et al. (2012, their Fig. 1). In Fig. 3, we see that the plasma beta is low in the polar cap region and increases with altitude. The average magnetopause for 2003 is predicted from the model

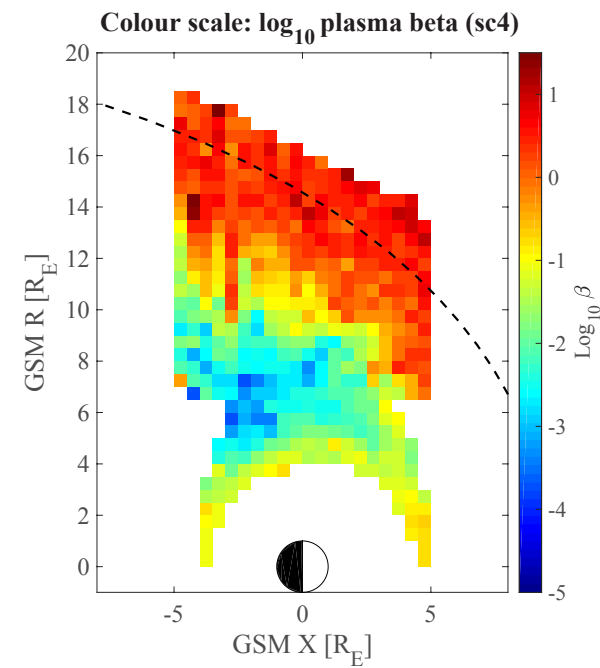

Figure 3. Average distribution of the plasma beta in cylindrical coordinates for 2003, storms included. The $\beta$ is low for high-altitude regions, i.e. the polar cap, then increases again, which corresponds to the cusp and plasma mantle region with $\log _{10}(\beta)>0.1$. The dashed line represents the prediction of the average magnetopause by Shue et al. (1998) during 2003.

of Shue et al. (1998) and the red region or $\log _{10}(\beta)>0.1$ corresponds to the cusp and plasma mantle. Comparing with the results of Nilsson et al. (2012, their Fig. 1), we see that the plasma beta increases with altitude, as does the scaled ionospheric flux. Note that in their Fig. 1, sampling is not along a given magnetic field line; therefore, the scaled ionospheric flux is not conserved with altitude. Thus, for this region of geospace, a region of similar $\beta$ typically corresponds to similar outflow along a similar flight trajectory from the source (cusp or polar cap). This can be further investigated using Fig. 4, where we present the distribution of the scaled oxygen ion outflow for each interval of plasma beta during 2003 (storm included) in (a). The colour scale represents the percentage of the scaled $\mathrm{O}^{+}$outflow for each interval of $\beta$. The columns are normalized so that the sum of all data in a column equals $100 \%$, and the colour scale is in per cent. Figure 4 shows a linear relation between the scaled $\mathrm{O}^{+}$outflow and the plasma beta, where lower $\beta$ corresponds to the polar cap and higher $\beta$ (above 0.1) to the plasma mantle and cusp. Spatial boxes with a similar plasma beta range thus corresponds to a region with, on average, comparable outflow from the ionosphere. Furthermore, the linear relationship means that if the scaled outflow for the extreme event stands out significantly from the year's average but $\beta$ does not, then we can say with confidence that the enhanced scaled outflow is not because we are sampling an entirely different region. The plasma beta can be expected to increase to some extent for the extreme event because the plasma density and temperature are higher than on average. Note that $\beta$ is calculated at the observation point, so the scaling of the ion flux to 

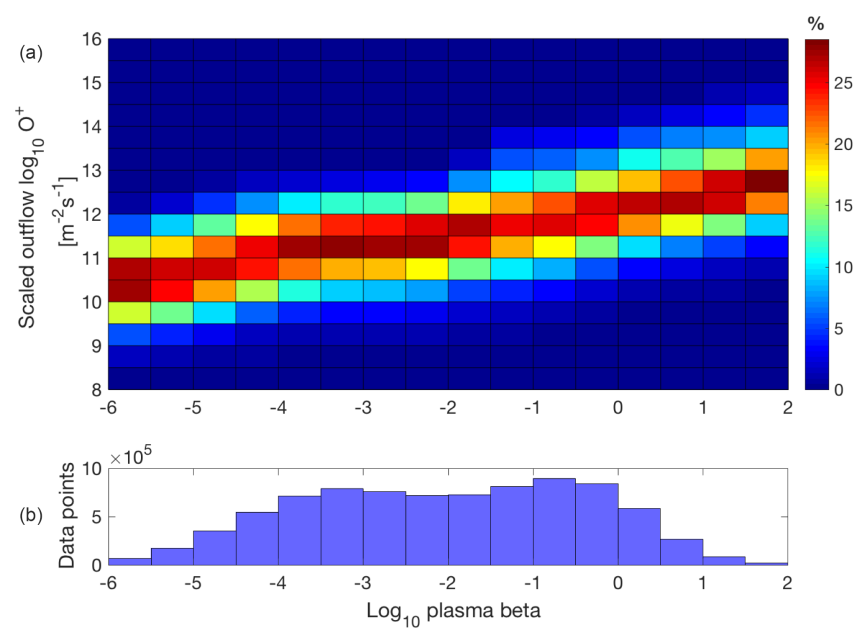

Figure 4. (a) Distribution of scaled oxygen ion outflow $\left(\mathrm{m}^{-2} \mathrm{~s}^{-1}\right)$ for each interval of plasma beta during 2003, including storms events. The colour scale represents the percentage of scaled $\mathrm{O}^{+}$ outflow for each interval of plasma beta. Each column is normalized so that the sum of the data equals $100 \%$ and the colour scale is in per cent. (b) Number of data points contributing to each column.

ionospheric altitude does not affect the plasma beta calculation. This particular relation between plasma beta and scaled oxygen ion outflow is valid for our Cluster data set in our sampling region; it is not necessarily true for the magnetosphere as a whole. Panel (b) shows the number of data points contributing to the corresponding column in (a).

After verifying the plasma beta range (less than 0.1 , so corresponding to the polar cap for all our cases) within the box for the extreme event and during the year, the average oxygen ion outflow during the year 2003 (including the storm) is computed and projected in 2-D (not shown). We check whether the major geomagnetic storm stands out from the less disturbed conditions and if there is an enhancement in $\mathrm{O}^{+}$. Finally, to visualize and estimate the enhancement, the oxygen ion outflow, scaled to an ionospheric reference level, is plotted using histograms separating the $\mathrm{O}^{+}$storm population from the entire $\mathrm{O}^{+}$population during the year of the storm. This final step is shown in more detail in Sect. 4 together with the other major storms considered in this study.

\section{Observations}

The relative enhancement of oxygen ion is investigated during six separate intense geomagnetic storms between 2001 and 2004. Three storms were observed around April-May, months with a high occurrence rate for geomagnetic storms (Zhang et al., 2007): 29-31 March and 11-12 April 2001 and 29-30 May 2003. Moreover, October and November have a higher storm occurrence rate (Zhang et al., 2007) and are months when three other storms were investigated: the Halloween event or 28-30 October 2003 as well as 7-8 and 9-11
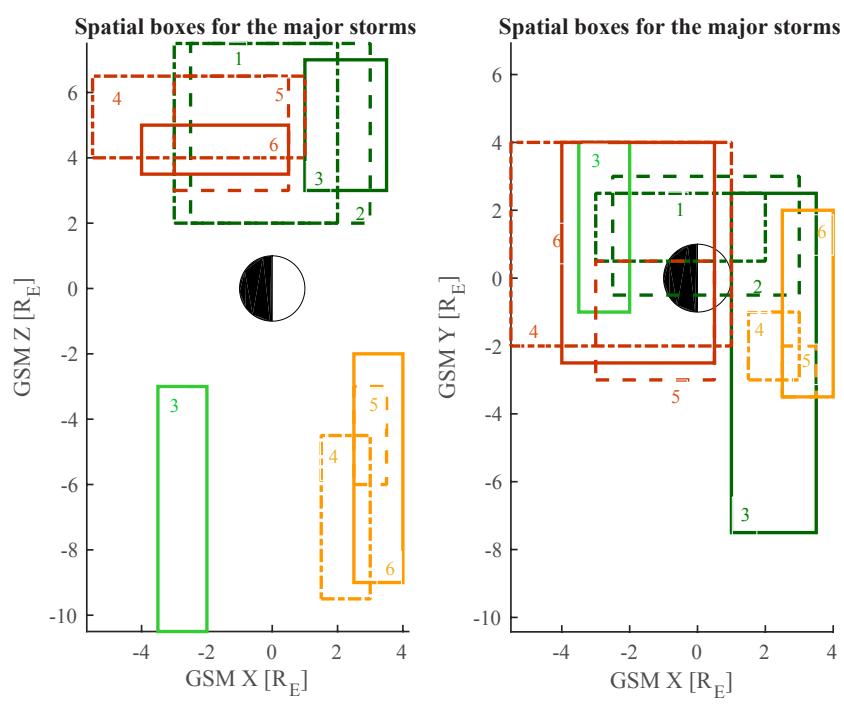

Figure 5. Spatial boxes are defined for each major geomagnetic storm. This figure shows all the individual spatial boxes that defined the location of the open magnetic field line region during each storm. The events are divided into the April-May storms and October-November storms. For the April-May storms, the scaled outflow regions in Northern and Southern Hemispheres are represented in dark green and in light green respectively. In the same way, orange corresponds to the outflow region in the north of the October-November storms and red to the outflow region in the south. Finally, each storm in these two groups is distinguished by different lines (dot-dashed, dashed and full). The numbers from 1 to 6 refer to Table 1, which identifies the storms.

November 2004. With an orbit period of $57 \mathrm{~h}$, Cluster crossed the polar caps and the plasma mantle and cusp only for a few hours during the storms; therefore, the amount of data for each individual event is limited.

These six major storms and different aspects of them have been studied and presented in a large number of papers, e.g. Baker et al. (2002), Wang et al. (2003), Hanuise et al. (2006), Rosenqvist et al. (2005), Tsurutani et al. (2008), Foster et al. (2002), Zhang et al. (2007), Echer et al. (2010) and Yermolaev et al. (2008). The storm conditions are summarized in Table 1. The six storms are listed in chronological order, numbered 1 to 6 . We determine the storm dates according to the position of the Cluster spacecraft at the dayside. The duration of each passage and the spacecraft used are given by the second and third row respectively. The Dst and Kp indices are two different indices, which describe the intensity of a geomagnetic storm and the magnetospheric conditions respectively. However, Dst is an hourly index while $\mathrm{Kp}$ is a $3 \mathrm{~h}$ index. The $\mathrm{PC}$ index gives the enhancement in the polar cap. Table 1 gives the minimum Dst index, the highest $\mathrm{Kp}$, the PC index, and the solar wind speed and density for the corresponding day. Finally, the average values for the event and the year as well as the mean ratio event / year of the solar radio flux at the wavelength of $10.7 \mathrm{~cm}$ (or F10.7 index; 
this index is a proxy for solar extreme ultraviolet flux) are calculated.

Section 3 describes how the outflow regions are defined, and in Fig. 5, we present the spatial boxes corresponding to all events in this study. Axes are in $R_{\mathrm{E}}$ in the GSM coordinates system and the Earth is represented in the middle of the panels. The numbers 1 to 6 and the associated boxes in Fig. 5 correspond to the numbering of the events in Table 1. The dark and light green rectangles correspond to the April-May storms, where each storm is shown as dot-dashed, dashed or solid lines, numbered 1 to 3 , whereas the red and orange rectangles correspond to the October-November storms, also defined by dot-dashed, dashed or solid lines and numbered 4 to 6 . Therefore, lines, numbers and colours together define one particular outflow region (in $\mathrm{NH}$ or $\mathrm{SH}$ ) for one of the six geomagnetic storms.

The scaled oxygen ion outflow during the extreme events is estimated in the spatial boxes (see Fig. 5). Figure 6 shows histograms of 1 year of scaled $\mathrm{O}^{+}$outflow in these boxes for each considered storm event in the Northern Hemisphere. The $x$ and $y$ axes correspond to the logarithmic values of the oxygen ion outflow scaled to the ionosphere and the number of data points respectively. The data covering the whole year of the storm are represented by blue bars, while the yellow bars correspond to the storm itself. In November 2004, several geomagnetic storms occurred in a short period. Hence, the middle and right panels in row (b) display two storms: 7 November (in yellow) and 10 November 2004 (in white and red). A common feature of all the events is an enhancement in the scaled oxygen ion outflow during the storms compared to the background data. In the same way, the scaled $\mathrm{O}^{+}$outflow is shown for the SH in Fig. 7, where enhancements in the scaled $\mathrm{O}^{+}$outflow for the storm are clearly visible as a separate peak in the distribution toward the largest fluxes observed.

The relative scaled $\mathrm{O}^{+}$outflow enhancements during the storms compared to less disturbed conditions can readily be obtained from Figs. 6 and 7 and are presented in Table 1. The median and mean taken from the histograms in Figs. 6 and 7 are listed as well as the ratio between the event mean/median and the year mean/median, which gives the relative enhancement. The median and mean values are expressed in $\mathrm{m}^{-2} \mathrm{~s}^{-1}$. Due to different boxes used for different events, the estimated scaled $\mathrm{O}^{+}$outflow during the same year is not identical for different events. The last row displays the highest scaled $\mathrm{O}^{+}$ outflow for each extreme event, with a minimum of 10 data points in the bin (Figs. 6 and 7).

\section{Discussion}

\subsection{Geomagnetic activity}

The main purpose of this study is to quantify the relative enhancement of the scaled $\mathrm{O}^{+}$outflow during major geomag- netic storms. Figures 6 and 7 present the upward $\mathrm{O}^{+}$flux scaled to an ionospheric altitude for six major geomagnetic storms and the year when they occurred. This scaled $\mathrm{O}^{+}$outflow is calculated in a spatial box which is defined by the spacecraft trajectory (position) during the storm. Note that we also observe plasma-sheet-like earthward return flux for two cases. Our boxes therefore contain a small fraction of plasma observed on closed field magnetic lines, for example due to tail flapping. These data are removed from our data set since we are only considering outflow.

The magnetosphere may be compressed during storms, so that observations during storms may be closer to the magnetopause. On the other hand, the cusp and plasma mantle also moves equatorward (Newell et al., 1989; Newell and Meng, 1994), and therefore our observations are in the polar cap further from the storm main outflow region. As a consequence, during storm time, the polar cap area is extended 2 or 3 times more than during quiet conditions (Li et al., 2012). Consequently, the spatial box might represent another region during the year when the storm occurred rather than the outflow region defined for the storm. This issue was dealt with in two ways. We demanded that the local plasma beta range was similar for the extreme event and the average for the whole year. We also compared the scaled ionospheric flux, thus compensating for any effect of a direct local compression of the magnetic field, which would enhance the local flux. This combined with the fact that the ionospheric source region, the polar cap, is much larger during a storm strongly indicates that the enhanced scaled flux during the storm corresponds to increased scaled outflow in the spatial box we study.

To look at this in more detail, we refer again to Figs. 3 and 4 . These figures show how the scaled $\mathrm{O}^{+}$outflow changes for different plasma beta, where $\beta<0.1$ usually corresponds to the polar cap regions while higher $\beta$ represents typically the cusp and plasma mantle. The scaled $\mathrm{O}^{+}$outflow as a function of the plasma beta parameter displays roughly a linear relation (Fig. 4), showing that when averaged over all conditions, we have a rather smooth variation of scaled outflow as function of plasma beta and more scaled outflow in the cusp and mantle as known from previous studies, e.g. Nilsson et al. (2012). If the magnetosphere was strongly compressed so that the spatial box was located in the polar cap for the average conditions (year) but in the plasma mantle and cusp for the extreme event, then we could expect that the plasma beta of the extreme event would stand out compared to the average conditions during the year in a similar way that the scaled $\mathrm{O}^{+}$outflow for the extreme event stands out. If instead the expansion of the polar cap is more important, then the extreme event is located further into the polar cap, away from the main outflow channel, the cusp and plasma mantle. In such a case we may not see a strong difference in the plasma beta, but the scaled outflow enhancement observed would be even more significant and our observations would be an underestimation of the actual enhancement. For exam- 


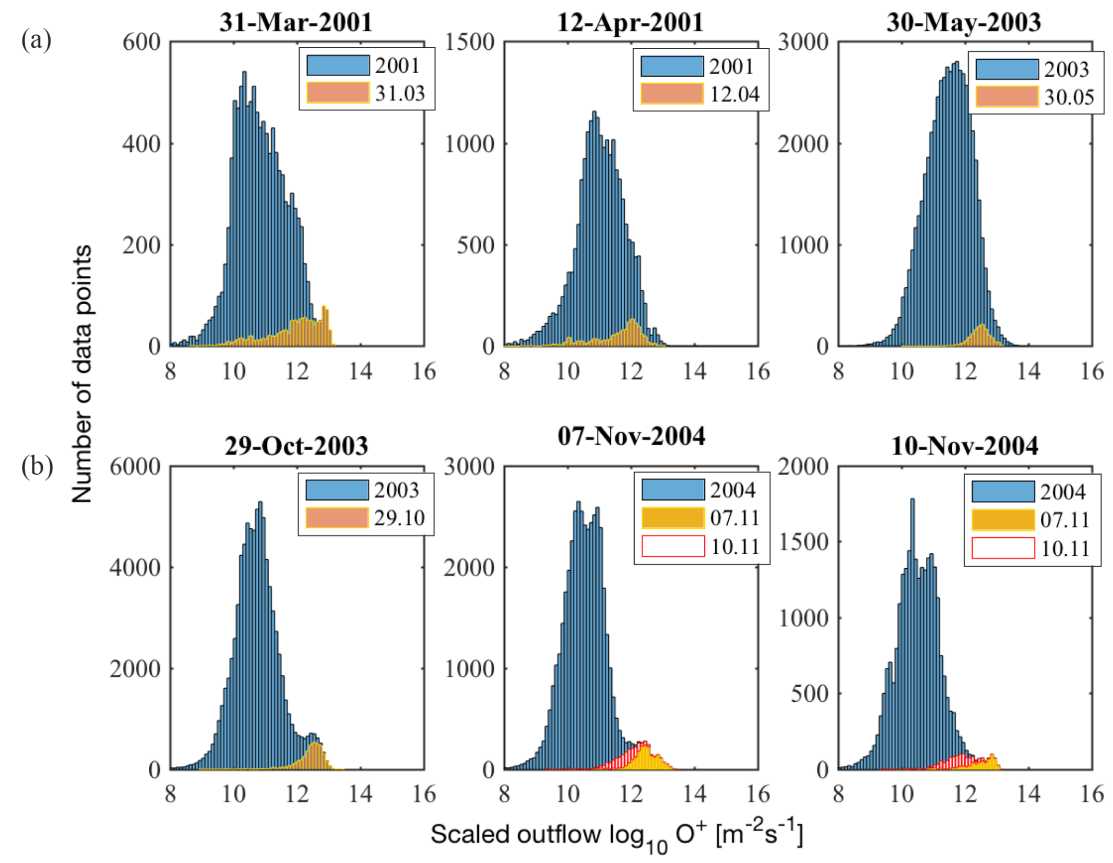

Figure 6. Histograms of the scaled $\mathrm{O}^{+}$outflow in logarithmic scale for the outflow region in the Northern Hemisphere. Each panel shows 1 year of data and one of the six geomagnetic storms. The three top panels (a) are the April-May storms, and the October-November storms are shown in the bottom panels (b). The blue bars correspond to 1 year of data (year of the storm) with all the storms during that year included, and the yellow bars represent the storms themselves. Each histogram is computed with the spatial box related to the extreme event.

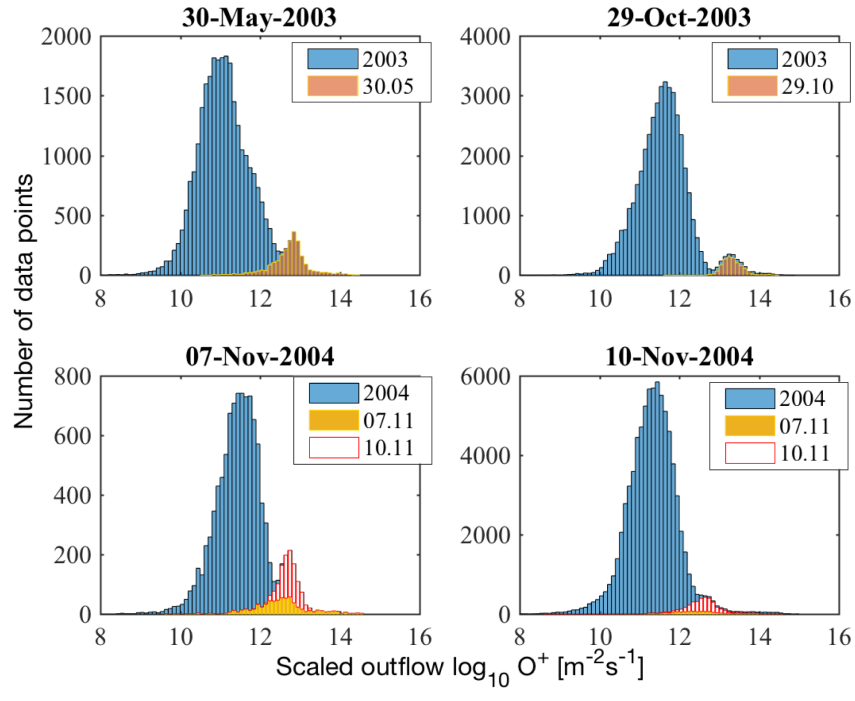

Figure 7. Same as Fig. 6 but for the outflow region in the Southern Hemisphere. However, only four storms have data during Cluster perigee.

ple, the year of our most extreme geomagnetic storm, the Halloween storm, has a scaled $\mathrm{O}^{+}$outflow of approximately $10^{11} \mathrm{~m}^{-2} \mathrm{~s}^{-1}$ (see Table 1), typical for the polar cap (see also Nilsson et al., 2013, for typical fluxes in different regions). There was an insignificant amount of data points in the cusp and plasma mantle $(\beta>0.1)$ also for the storms; therefore, the amount of data that could be located outside the intended magnetospheric region does not affect the statistics.

In Table 1 , the scaled $\mathrm{O}^{+}$outflow during geomagnetic storms ranges between $3.5 \times 10^{11}$ and $2.1 \times 10^{13} \mathrm{~m}^{-2} \mathrm{~s}^{-1}$, which is related to the intensity of the storm and subsequently with the Kp and F10.7 index (discussed below). We have estimated the average scaled $\mathrm{O}^{+}$outflow in the open field line region to be $10^{12} \mathrm{~m}^{-2} \mathrm{~s}^{-1}$ during storm time. Our results are consistent with previous observations made by $\mathrm{Ki}$ tamura et al. (2010), who determined the average of cold oxygen ion fluxes in the polar cap during two major geomagnetic storms (30 March and 17 April 1990). They obtained $2.1 \times 10^{13} \mathrm{~m}^{-2} \mathrm{~s}^{-1}$ for the first event and between $4 \times 10^{12}-4 \times 10^{13} \mathrm{~m}^{-2} \mathrm{~s}^{-1}$ for 17 April 1990. However, the scaled $\mathrm{O}^{+}$outflow that we estimate is not considerably higher than during less disturbed conditions. Indeed, Nilsson et al. (2012) found that the oxygen ion flux at a high cusp altitude is $5 \times 10^{12} \mathrm{~m}^{-2} \mathrm{~s}^{-1}$, and Lennartsson et al. (2004) observed $\mathrm{O}^{+}$flux in the cusp regions of approximately $10^{12} \mathrm{~m}^{-2} \mathrm{~s}^{-1}$ above $65^{\circ}$ invariant latitude. However, we observe significant relative scaled outflow enhancements from a factor of 3 to 83 (or 0.5 to approximately 2 orders of magnitude) in Figs. 6 and 7. This considerable difference is associated with the geomagnetic indices $\mathrm{Kp}$ given in Table 1 . The mean ratio of the F10.7 index between the event and the corresponding year is up to about 2 times larger than usual for geomagnetic storms with $\mathrm{Kp}>8$. The index has no discernible trend on a 1-year scale, so that the ratios vary 
Table 1. Features of the six major geomagnetic storms. Each column corresponds to one storm, while each row corresponds to one feature. The storms are given in chronological order, with one number assigned for each storm. The duration (in UT) is the time taken to study the storm during Cluster passage at the dayside. The second row gives the spacecraft used for each event. Dst, Kp, the PC index, and solar wind (SW) speed and density are the highest values taking during the corresponding day. The average values for the event and the year and the mean ratio event / year of the F10.7 index are calculated. The year / event mean or median are calculated from the histograms shown in Figs. 6 and 7 respectively in the Northern and Southern Hemispheres (NH and SH). The mean and median are expressed in $\mathrm{m}^{-2} \mathrm{~s}^{-1}$.

\begin{tabular}{|c|c|c|c|c|c|c|}
\hline & 1 & 2 & 3 & 4 & 5 & 6 \\
\hline Dates & 31 Mar 2001 & 12 Apr 2001 & 29-30 May 2003 & 29 Oct 2003 & 07 Nov 2004 & 09-10 Nov 2004 \\
\hline Duration (UT) & 06:00-14:00 & 02:00-19:00 & 22:00-16:00 & 08:30-20:00 & 14:00-22:00 & 20:00-10:00 \\
\hline Spacecraft & 1 & 3 & 1 & 4 & 4 & 4 \\
\hline Dst index (nT) & -387 & -271 & -144 & -350 & -117 & -259 \\
\hline Kp index & 9- & $7+$ & $7+$ & 9 & 8 & 9- \\
\hline $\mathrm{PC}$ index & 12.7 & 6.4 & 4.8 & 12.8 & 12 & 11.7 \\
\hline SW speed $\left(\mathrm{km} \mathrm{s}^{-1}\right)$ & 723 & 722 & 813 & - & 696 & 794 \\
\hline SW density $\left(\mathrm{N} \mathrm{cm}^{3}\right)$ & 37.9 & 4.4 & 52.2 & - & 90.2 & 18.0 \\
\hline Average F10.7 (e & 245.3 & 149.8 & 121.56 & 275.4 & 127.2 & 110.21 \\
\hline Average F10.7 (year) & 181.1 & 181.1 & 128.45 & 128.45 & 106.53 & 106.53 \\
\hline Mean ratio F10.7 & 1.3545 & 0.8272 & 0.9465 & 2.1440 & 1.1941 & 1.0346 \\
\hline Year mean value & $\mathrm{NH} 7.9 \times 10^{10}$ & $\mathrm{NH} 1.1 \times 10^{11}$ & $\mathrm{NH} 3.1 \times 10^{11}$ & NH $5.9 \times 10^{10}$ & $\mathrm{NH} 4 \times 10^{10}$ & $\mathrm{NH} 3.5 \times 10^{10}$ \\
\hline$\left(m^{-2} s^{-1}\right)$ & - & - & SH $1.5 \times 10^{11}$ & $\mathrm{SH} 4.1 \times 10^{11}$ & SH $3.6 \times 10^{11}$ & SH $2.2 \times 10^{11}$ \\
\hline Year median value & $\mathrm{NH} 6.6 \times 10^{10}$ & $\mathrm{NH} 1.1 \times 10^{11}$ & $\mathrm{NH} 3.4 \times 10^{11}$ & $\mathrm{NH} 5.3 \times 10^{10}$ & $\mathrm{NH} 3.6 \times 10^{10}$ & $\mathrm{NH} 3.2 \times 10^{10}$ \\
\hline$\left(\mathrm{m}^{-2} \mathrm{~s}^{-1}\right)$ & - & - & SH $1.3 \times 10^{11}$ & SH $4 \times 10^{11}$ & SH $3.4 \times 10^{11}$ & SH $2.2 \times 10^{11}$ \\
\hline Event mean value & $\mathrm{NH} 8.7 \times 10^{11}$ & $\mathrm{NH} 3.5 \times 10^{11}$ & $\mathrm{NH} 3 \times 10^{12}$ & NH $2.6 \times 10^{12}$ & NH $2.8 \times 10^{12}$ & NH $5.6 \times 10^{11}$ \\
\hline$\left(m^{-2} s^{-1}\right)$ & - & - & SH $5.6 \times 10^{12}$ & SH $2.1 \times 10^{13}$ & SH $3.3 \times 10^{12}$ & SH $3.8 \times 10^{12}$ \\
\hline Event median value & $\mathrm{NH} 1.3 \times 10^{12}$ & NH $6.5 \times 10^{11}$ & $\mathrm{NH} 3.1 \times 10^{12}$ & $\mathrm{NH} 3.2 \times 10^{12}$ & NH $3 \times 10^{12}$ & $\mathrm{NH} 5.8 \times 10^{11}$ \\
\hline$\left(\mathrm{m}^{-2} \mathrm{~s}^{-1}\right)$ & - & - & SH $6.2 \times 10^{12}$ & SH $2 \times 10^{13}$ & SH $3.4 \times 10^{12}$ & $\mathrm{SH} 4 \times 10^{12}$ \\
\hline Mean ratio & NH 11 & NH 3 & NH 10 & $\mathrm{NH} 44$ & NH 70 & NH 16 \\
\hline (event / year) & - & - & SH 37 & SH 51 & SH 9 & SH 17 \\
\hline Median ratio & NH 20 & NH 6 & NH 9 & NH 60 & NH 83 & NH 18 \\
\hline (event / year) & - & - & SH 47 & SH 50 & SH 10 & SH 18 \\
\hline Highest scaled $\mathrm{O}^{+}$outflow & $\mathrm{NH} 1.3 \times 10^{13}$ & NH $6.3 \times 10^{12}$ & $\mathrm{NH} 1.6 \times 10^{13}$ & $\mathrm{NH} 1.6 \times 10^{13}$ & $\mathrm{NH} 2 \times 10^{13}$ & $\mathrm{NH} 4 \times 10^{12}$ \\
\hline (event) $\left(\mathrm{m}^{-2} \mathrm{~s}^{-1}\right)$ & - & - & SH $1.6 \times 10^{14}$ & $\mathrm{SH} 2 \times 10^{14}$ & SH $8 \times 10^{13}$ & SH $3.2 \times 10^{13}$ \\
\hline
\end{tabular}

in a small range. Therefore, it appears that the varying solar cycle trend over the year does not affect our results. One of the strongest storms, the Halloween event (number 4 in Table 1), has the highest scaled $\mathrm{O}^{+}$outflow ( $\left.\mathrm{SH}\right), \mathrm{Kp}$ and F10.7 index. This strongest enhancement in scaled $\mathrm{O}^{+}$outflow for the storm is approximately 2 orders of magnitude higher than during less disturbed magnetospheric conditions. In addition, the Halloween storm occurred near the solar maximum where increased oxygen flux has been observed in the past (Yau and Andre, 1997). This result is consistent with Yau et al. (1988), who showed a Kp dependence on the $\mathrm{O}^{+}$flux at lower altitudes, and with Slapak et al. (2017), who studied the oxygen ion escape from the plasma mantle and cusp and its dependence on the geomagnetic activity. Slapak et al. (2017) found that in the plasma mantle and the dayside magnetosheath, the scaled $\mathrm{O}^{+}$outflow increases exponentially as $\exp (0.45 \mathrm{Kp})$. In the plasma mantle, they observed an increase of 1.5 orders of magnitude for the scaled oxygen ion outflow between average conditions $(\mathrm{Kp} \approx 3)$ and highest geomagnetic activities. In comparison with Slapak et al. (2017, their Fig. 4), who show the distribution of $\mathrm{O}^{+}$observations over $\mathrm{Kp}$ for the plasma mantle and the dayside mag- netosheath, we estimate a lower scaled $\mathrm{O}^{+}$outflow, which is reasonable because our region of observations is in the polar cap. We also note that due to the Cluster orbit, suitable data are not always obtained from the period of highest geomagnetic activity for each storm. Similar enhancements in the $\mathrm{O}^{+}$density with geomagnetic activity in the near-Earth tail plasma sheet have been reported by Lennartsson and Shelley (1986), Mouikis et al. (2010), and Maggiolo and Kistler (2014).

Unfortunately, we were not able to confirm that this scaled outflow enhancement is escaping because our observations are made in the polar cap and the average velocities do not confirm a clear $\mathrm{O}^{+}$escape tendency. However, this result of a scaled outflow enhancement during major geomagnetic storms shows that there is a strong relative enhancement in the regions where we have Cluster observations. Slapak et al. (2017) used the Halloween event $\mathrm{Kp}$ index as a reference to estimate the total $\mathrm{O}^{+}$loss over 4 billion years. Their result gives a total $\mathrm{O}^{+}$loss 1.3 times the total oxygen mass in the present atmosphere. Our patchy observations from parts of the magnetosphere are consistent with the escape value extrapolated from their data. 


\subsection{Most extreme case}

During geomagnetic storms, the polar cap is moving equatorward, and subsequently the main outflow region moves as well compared to the average outflow region. In this paper, we are mostly not in the main outflow region of the storm. During the six events (see Table 1) in the $\mathrm{NH}$ and $\mathrm{SH}$, we calculate the highest scaled $\mathrm{O}^{+}$outflow. There is a 1 order of magnitude difference between the $\mathrm{SH}$ and $\mathrm{NH}$, which could be explained by the different relative location of the spatial boxes and the geomagnetic activity. A similar trend has been observed by Luo et al. (2017), who studied the energetic ion distributions in the dayside magnetosphere and the plasma sheet. The authors found that there is a strong correlation between the dawn-dusk asymmetry and the IMF direction, with a higher asymmetry in the Southern Hemisphere. The highest scaled $\mathrm{O}^{+}$outflow value for the six events is $2 \times 10^{14} \mathrm{~m}^{-2} \mathrm{~s}^{-1}$ observed in the 29 October SH spatial box. This result is 2 orders of magnitude higher than what is observed during average conditions $(\mathrm{Kp} \approx 3)$ (Nilsson et al., 2012); therefore, the upper limit of scaled $\mathrm{O}^{+}$outflow during the storm peak is probably more intense. The scaled $\mathrm{O}^{+}$outflow is lower in the $\mathrm{NH}$ than in the $\mathrm{SH}$, and the upper limit in the $\mathrm{NH}$ is $2 \times 10^{13} \mathrm{~m}^{-2} \mathrm{~s}^{-1}$ (event number 5) for our cases.

\section{Conclusions}

Using Cluster CODIF data between 2001 and 2004, we have calculated the upward $\mathrm{O}^{+}$flux scaled to an ionospheric reference altitude for six major geomagnetic storms (Dst $\leq-100 \mathrm{nT}$ or $\mathrm{Kp} \geq 7+$ ). The scaled $\mathrm{O}^{+}$outflow is estimated for the storms themselves and for 1 year of data (the year when the storm occurred) in the region corresponding to the storm observations in the Northern and Southern Hemispheres. The main result is a clear relative enhancement in the scaled $\mathrm{O}^{+}$outflow by a factor of 3 to 83 during storm times, indicating that the entire magnetospheric circulation increases significantly during extreme events. The upper limit for the scaled $\mathrm{O}^{+}$outflow was found in the Southern Hemisphere for 29 October 2003, with $2 \times 10^{14} \mathrm{~m}^{-2} \mathrm{~s}^{-1}$ (Halloween event). Cluster was not located in the main outflow region (the cusp and plasma mantle) during any of the investigated storms. Therefore, we are not able to estimate the total escape. However, the scaled $\mathrm{O}^{+}$outflow for the extreme events stood out from the general distribution as a bump in the tail of the distribution. Thus, there is an extreme enhancement of the scaled outflow in the regions investigated. Furthermore, the relative scaled outflow enhancements vary with the $\mathrm{Kp}$ index in a way that is consistent with Slapak et al. (2017), who show the Kp dependence on escaping $\mathrm{O}^{+}$ scaled outflow in the plasma mantle. Our results show a general increase in the magnetospheric scaled $\mathrm{O}^{+}$outflow of 2 orders of magnitude for the most intense geomagnetic storms and thus support the estimation of Slapak et al. (2017) of a 2 orders of magnitude increase in the total escape for highest geomagnetic activity $(\mathrm{Kp} \geq 8)$. Thus, the escape during extreme events which occur only rarely can still have a significant effect on the total outflow, in particularly for ancient solar conditions when such events are expected to have been more common. Our main results can be summarized as follows:

1. we observe a clear relative scaled outflow enhancement by a factor of 3 to 83 during the major geomagnetic storms in the polar cap region;

2. the upper limit of the scaled outflow during these storms is estimated to be $2 \times 10^{14} \mathrm{~m}^{-2} \mathrm{~s}^{-1}$ (during the Halloween event $\mathrm{SH}$ );

3. the general increase in the magnetospheric scaled $\mathrm{O}^{+}$ outflow supports the estimation of Slapak et al. (2017) of a 2 orders of magnitude increase for the total escape during extreme geomagnetic activity.

Data availability. All Cluster data are freely accessible and were retrieved from the Cluster Science Archive (https://www.cosmos. esa.int/web/csa/access). The geomagnetic indices Dst and Kp are freely accessible from the WDC for Geomagnetism, Kyoto (http: //wdc.kugi.kyoto-u.ac.jp/index.html), and the GFZ Adolf Schmidt Observatory, Niemegk (https://www.gfz-potsdam.de/en/kp-index/). Finally, the polar cap (PC), F10.7 indices and the solar wind data are freely accessible and were retrieved from the OMNIWeb database (https://omniweb.gsfc.nasa.gov).

Competing interests. The authors declare that they have no conflict of interest.

Acknowledgements. The authors want to thank the Swedish Institute of Space Physics, the Graduate School of Space Technology in Luleå and the Swedish National Space Board for financial support. We also want to thank the Cluster CODIF and FGM instrument teams for providing data that can be freely retrieved from the Cluster Science Archive. The geomagnetic indices Dst and $\mathrm{Kp}$ for the storms are taken from the WDC for Geomagnetism, Kyoto, and the GFZ Postdam official Kp index. PC, F10.7 indices and solar wind data are taken from the free OMNI database.

The topical editor, Christopher Owen, thanks Stein Haaland and one anonymous referee for help in evaluating this paper.

\section{References}

Axford, W. I.: The polar wind and the terrestrial helium budget, J. Geophys. Res., 73, 6855-6859, https://doi.org/10.1029/JA073i021p06855, 1968.

Baker, D. N., Ergun, R. E., Burch, J. L., Jahn, J.-M., Daly, P. W., Friedel, R., Reeves, G. D., Fritz, T. A., and Mitchell, 
D. G.: A telescopic and microscopic view of a magnetospheric substorm on 31 March 2001, Geophys. Res. Lett., 29, 1862, https://doi.org/10.1029/2001GL014491, 2002.

Balogh, A., Carr, C. M., Acuña, M. H., Dunlop, M. W., Beek, T. J., Brown, P., Fornacon, K.-H., Georgescu, E., Glassmeier, K.H., Harris, J., Musmann, G., Oddy, T., and Schwingenschuh, K.: The Cluster Magnetic Field Investigation: overview of in-flight performance and initial results, Ann. Geophys., 19, 1207-1217, https://doi.org/10.5194/angeo-19-1207-2001, 2001.

Chappell, C. R., Moore, T. E., and Waite, Jr., J. H.: The ionosphere as a fully adequate source of plasma for the earth's magnetosphere, J. Geophys. Res., 92, 5896-5910, https://doi.org/10.1029/JA092iA06p05896, 1987.

Echer, E., Tsurutani, B. T., and Guarnieri, F. L.: Interplanetary origins of November 2004 superstorms, J. Atmos. Sol.-Terr. Phy., 72, 280-284, https://doi.org/10.1016/j.jastp.2009.02.009, 2010.

Engwall, E., Eriksson, A. I., André, M., Dandouras, I., Paschmann, G., Quinn, J., and Torkar, K.: Low-energy (order $10 \mathrm{eV}$ ) ion flow in the magnetotail lobes inferred from spacecraft wake observations, Geophys. Res. Lett., 33, L06110, https://doi.org/10.1029/2005GL025179, 2006.

Escoubet, C. P., Fehringer, M., and Goldstein, M.: Introduction The Cluster mission, Ann. Geophys., 19, 1197-1200, https://doi.org/10.5194/angeo-19-1197-2001, 2001.

Foster, J. C., Erickson, P. J., Coster, A. J., Goldstein, J., and Rich, F. J.: Ionospheric signatures of plasmaspheric tails, Geophys. Res. Lett., 29, 1623, https://doi.org/10.1029/2002GL015067, 2002.

Haaland, S., Eriksson, A., Engwall, E., Lybekk, B., Nilsson, H., Pedersen, A., Svenes, K., André, M., Förster, M., Li, K., Johnsen, C., and Østgaard, N.: Estimating the capture and loss of cold plasma from ionospheric outflow, J. Geophys. Res.-Space, 117, A07311, https://doi.org/10.1029/2012JA017679, 2012.

Haaland, S., Eriksson, A., André, M., Maes, L., Baddeley, L., Barakat, A., Chappell, R., Eccles, V., Johnsen, C., Lybekk, B., Li, K., Pedersen, A., Schunk, R., and Welling, D.: Estimation of cold plasma outflow during geomagnetic storms, J. Geophys. Res.-Space, 120, 10622-10639, https://doi.org/10.1002/2015JA021810, 2015.

Hanuise, C., Cerisier, J. C., Auchère, F., Bocchialini, K., Bruinsma, S., Cornilleau-Wehrlin, N., Jakowski, N., Lathuillère, C., Menvielle, M., Valette, J.-J., Vilmer, N., Watermann, J., and Yaya, P.: From the Sun to the Earth: impact of the 27-28 May 2003 solar events on the magnetosphere, ionosphere and thermosphere, Ann. Geophys., 24, 129-151, https://doi.org/10.5194/angeo-24129-2006, 2006.

Kamide, Y., Baumjohann, W., Daglis, I. A., Gonzalez, W. D., Grande, M., Joselyn, J. A., McPherron, R. L., Phillips, J. L., Reeves, E. G. D., Rostoker, G., Sharma, A. S., Singer, H. J., Tsurutani, B. T., and Vasyliunas, V. M.: Current understanding of magnetic storms: Storm-substorm relationships, J. Geophys. Res., 103, 17705-17728, https://doi.org/10.1029/98JA01426, 1998.

Kistler, L. M., Mouikis, C. G., Cao, X., Frey, H., Klecker, B., Dandouras, I., Korth, A., Marcucci, M. F., Lundin, R., McCarthy, M., Friedel, R., and Lucek, E.: Ion composition and pressure changes in storm time and nonstorm substorms in the vicinity of the near-Earth neutral line, J. Geophys. Res.-Space, 111, A11222, https://doi.org/10.1029/2006JA011939, 2006.
Kistler, L. M., Mouikis, C. G., Klecker, B., and Dandouras, I.: Cusp as a source for oxygen in the plasma sheet during geomagnetic storms, J. Geophys. Res.-Space, 115, A03209, https://doi.org/10.1029/2009JA014838, 2010.

Kitamura, N., Nishimura, Y., Ono, T., Ebihara, Y., Terada, N., Shinbori, A., Kumamoto, A., Abe, T., Yamada, M., Watanabe, S., Matsuoka, A., and Yau, A. W.: Observations of very-low-energy $(<10 \mathrm{eV})$ ion outflows dominated by $\mathrm{O}^{+}$ions in the region of enhanced electron density in the polar cap magnetosphere during geomagnetic storms, J. Geophys. Res.-Space, 115, A00J06, https://doi.org/10.1029/2010JA015601, 2010.

Krauss, S., Fichtinger, B., Lammer, H., Hausleitner, W., Kulikov, Yu. N., Ribas, I., Shematovich, V. I., Bisikalo, D., Lichtenegger, H. I. M., Zaqarashvili, T. V., Khodachenko, M. L., and Hanslmeier, A.: Solar flares as proxy for the young Sun: satellite observed thermosphere response to an X17.2 flare of Earth's upper atmosphere, Ann. Geophys., 30, 1129-1141, https://doi.org/10.5194/angeo-30-1129-2012, 2012.

Kronberg, E. A., Ashour-Abdalla, M., Dandouras, I., Delcourt, D. C., Grigorenko, E. E., Kistler, L. M., Kuzichev, I. V., Liao, J., Maggiolo, R., Malova, H. V., Orlova, K. G., Peroomian, V., Shklyar, D. R., Shprits, Y. Y., Welling, D. T., and Zelenyi, L. M.: Circulation of Heavy Ions and Their Dynamical Effects in the Magnetosphere: Recent Observations and Models, Space Sci. Rev., 184, 173-235, https://doi.org/10.1007/s11214-014-0104-0, 2014.

Lennartsson, O. W., Collin, H. L., and Peterson, W. K.: Solar wind control of Earth's $\mathrm{H}^{+}$and $\mathrm{O}^{+}$outflow rates in the $15-\mathrm{eV}$ to 33-keV energy range, J. Geophys. Res.-Space, 109, A12212, https://doi.org/10.1029/2004JA010690, 2004.

Lennartsson, W. and Shelley, E. G.: Survey of 0.1- to $16-\mathrm{keV} / \mathrm{e}$ plasma sheet ion composition, J. Geophys. Res., 91, 3061-3076, https://doi.org/10.1029/JA091iA03p03061, 1986.

Li, K., Haaland, S., Eriksson, A., André, M., Engwall, E., Wei, Y., Kronberg, E. A., Fränz, M., Daly, P. W., Zhao, H., and Ren, Q. Y.: On the ionospheric source region of cold ion outflow, Geophys. Res. Lett., 39, L18102, https://doi.org/10.1029/2012GL053297, 2012.

Liao, J., Kistler, L. M., Mouikis, C. G., Klecker, B., Dandouras, I., and Zhang, J.-C.: Statistical study of $\mathrm{O}^{+}$transport from the cusp to the lobes with Cluster CODIF data, J. Geophys. Res.-Space, 115, A00J15, https://doi.org/10.1029/2010JA015613, 2010.

Liao, J., Kistler, L. M., Mouikis, C. G., Klecker, B., and Dandouras, I.: Acceleration of $\mathrm{O}^{+}$from the cusp to the plasma sheet, J. Geophys. Res.-Space, 120, 1022-1034, https://doi.org/10.1002/2014JA020341, 2015.

Luo, H., Kronberg, E. A., Nykyri, K., Trattner, K. J., Daly, P. W., Chen, G. X., Du, A. M., and Ge, Y. S.: IMF dependence of energetic oxygen and hydrogen ion distributions in the nearEarth magnetosphere, J. Geophys. Res.-Space, 122, 5168-5180, https://doi.org/10.1002/2016JA023471, 2017.

Maggiolo, R. and Kistler, L. M.: Spatial variation in the plasma sheet composition: Dependence on geomagnetic and solar activity, J. Geophys. Res.-Space, 119, 2836-2857, https://doi.org/10.1002/2013JA019517, 2014.

Moore, T. E., Chappell, C. R., Chandler, M. O., Craven, P. D., Giles, B. L., Pollock, C. J., Burch, J. L., Young, D. T., Waite, Jr., J. H., Nordholt, J. E., Thomsen, M. F., McComas, D. J., Berthelier, J. J., Williamson, W. S., Robson, R., and Mozer, F. S.: High- 
altitude observations of the polar wind., Science, 277, 349-351, https://doi.org/10.1126/science.277.5324.349, 1997.

Mouikis, C. G., Kistler, L. M., Liu, Y. H., Klecker, B., Korth, A., and Dandouras, I.: $\mathrm{H}^{+}$and $\mathrm{O}^{+}$content of the plasma sheet at $15-19 \mathrm{Re}$ as a function of geomagnetic and solar activity, J. Geophys. Res.-Space, 115, A00J16, https://doi.org/10.1029/2010JA015978, 2010.

Newell, P. T. and Meng, C.-I.: Ionospheric projections of magnetospheric regions under low and high solar wind pressure conditions, J. Geophys. Res.-Space, 99, 273-286, https://doi.org/10.1029/93JA02273, 1994.

Newell, P. T., Meng, C.-I., Sibeck, D. G., and Lepping, R.: Some low-altitude cusp dependencies on the interplanetary magnetic field, J. Geophys. Res.-Space, 94, 8921-8927, https://doi.org/10.1029/JA094iA07p08921, 1989.

Nilsson, H.: Heavy Ion Energization, Transport, and Loss in the Earth's Magnetosphere, Springer Netherlands, Dordrecht, 315327, https://doi.org/10.1007/978-94-007-0501-2_17, 2011.

Nilsson, H., Waara, M., Arvelius, S., Marghitu, O., Bouhram, M., Hobara, Y., Yamauchi, M., Lundin, R., Rème, H., Sauvaud, J.-A., Dandouras, I., Balogh, A., Kistler, L. M., Klecker, B., Carlson, C. W., Bavassano-Cattaneo, M. B., and Korth, A.: Characteristics of high altitude oxygen ion energization and outflow as observed by Cluster: a statistical study, Ann. Geophys., 24, 1099-1112, https://doi.org/10.5194/angeo-24-1099-2006, 2006.

Nilsson, H., Engwall, E., Eriksson, A., Puhl-Quinn, P. A., and Arvelius, S.: Centrifugal acceleration in the magnetotail lobes, Ann. Geophys., 28, 569-576, https://doi.org/10.5194/angeo-28569-2010, 2010.

Nilsson, H., Barghouthi, I. A., Slapak, R., Eriksson, A. I., and André, M.: Hot and cold ion outflow: Spatial distribution of ion heating, J. Geophys. Res.-Space, 117, A11201, https://doi.org/10.1029/2012JA017974, 2012.

Nilsson, H., Barghouthi, I. A., Slapak, R., Eriksson, A. I., and André, M.: Hot and cold ion outflow: Observations and implications for numerical models, J. Geophys. Res.-Space, 118, 105-117, https://doi.org/10.1029/2012JA017975, 2013.

Rème, H., Aoustin, C., Bosqued, J. M., Dandouras, I., Lavraud, B., Sauvaud, J. A., Barthe, A., Bouyssou, J., Camus, Th., Coeur-Joly, O., Cros, A., Cuvilo, J., Ducay, F., Garbarowitz, Y., Medale, J. L., Penou, E., Perrier, H., Romefort, D., Rouzaud, J., Vallat, C., Alcaydé, D., Jacquey, C., Mazelle, C., d'Uston, C., Möbius, E., Kistler, L. M., Crocker, K., Granoff, M., Mouikis, C., Popecki, M., Vosbury, M., Klecker, B., Hovestadt, D., Kucharek, H., Kuenneth, E., Paschmann, G., Scholer, M., Sckopke, N., Seidenschwang, E., Carlson, C. W., Curtis, D. W., Ingraham, C., Lin, R. P., McFadden, J. P., Parks, G. K., Phan, T., Formisano, V., Amata, E., Bavassano-Cattaneo, M. B., Baldetti, P., Bruno, R., Chionchio, G., Di Lellis, A., Marcucci, M. F., Pallocchia, G., Korth, A., Daly, P. W., Graeve, B., Rosenbauer, H., Vasyliunas, V., McCarthy, M., Wilber, M., Eliasson, L., Lundin, R., Olsen, S., Shelley, E. G., Fuselier, S., Ghielmetti, A. G., Lennartsson, W., Escoubet, C. P., Balsiger, H., Friedel, R., Cao, J.-B., Kovrazhkin, R. A., Papamastorakis, I., Pellat, R., Scudder, J., and Sonnerup, B.: First multispacecraft ion measurements in and near the Earth's magnetosphere with the identical Cluster ion spectrometry (CIS) experiment, Ann. Geophys., 19, 1303-1354, https://doi.org/10.5194/angeo-19-1303-2001, 2001.
Ribas, I., Guinan, E. F., Güdel, M., and Audard, M.: Evolution of the Solar Activity over Time and Effects on Planetary Atmospheres. I. High-Energy Irradiances (1-1700 Å), Astrophys. J., 622, 680694, https://doi.org/10.1086/427977, 2005.

Rosenqvist, L., Opgenoorth, H., Buchert, S., McCrea, I., Amm, O., and Lathuillere, C.: Extreme solar-terrestrial events of October 2003: High-latitude and Cluster observations of the large geomagnetic disturbances on 30 October, J. Geophys. Res.-Space, 110, A09S23, https://doi.org/10.1029/2004JA010927, 2005.

Seki, K., Elphic, R. C., Hirahara, M., Terasawa, T., and Mukai, T.: On Atmospheric Loss of Oxygen Ions from Earth Through Magnetospheric Processes, AGU Spring Meeting Abstracts, 2001.

Shelley, E. G., Peterson, W. K., Ghielmetti, A. G., and Geiss, J.: The polar ionosphere as a source of energetic magnetospheric plasma, Geophys. Res. Lett., 9, 941-944, https://doi.org/10.1029/GL009i009p00941, 1982.

Shue, J.-H., Song, P., Russell, C. T., Steinberg, J. T., Chao, J. K., Zastenker, G., Vaisberg, O. L., Kokubun, S., Singer, H. J., Detman, T. R., and Kawano, H.: Magnetopause location under extreme solar wind conditions, J. Geophys. Res., 103, 17691-17700, https://doi.org/10.1029/98JA01103, 1998.

Slapak, R., Nilsson, H., and Westerberg, L. G.: A statistical study on $\mathrm{O}+$ flux in the dayside magnetosheath, Ann. Geophys., 31, 1005-1010, https://doi.org/10.5194/angeo-31-1005-2013, 2013.

Slapak, R., Schillings, A., Nilsson, H., Yamauchi, M., Westerberg, L.-G., and Dandouras, I.: Atmospheric loss from the dayside open polar region and its dependence on geomagnetic activity: implications for atmospheric escape on evolutionary timescales, Ann. Geophys., 35, 721-731, https://doi.org/10.5194/angeo-35721-2017, 2017.

Tsurutani, B. T., Echer, E., Guarnieri, F. L., and Kozyra, J. U.: CAWSES November 7-8, 2004, superstorm: Complex solar and interplanetary features in the post-solar maximum phase, Geophys. Res. Lett., 35, L06S05, https://doi.org/10.1029/2007GL031473, 2008.

Wang, Y. M., Ye, P. Z., and Wang, S.: Multiple magnetic clouds: Several examples during March-April 2001, J. Geophys. Res.Space, 108, 1370, https://doi.org/10.1029/2003JA009850, 2003.

Yau, A. W. and Andre, M.: Sources of Ion Outflow in the High Latitude Ionosphere, Space Sci. Rev., 80, 1-25, https://doi.org/10.1023/A:1004947203046, 1997.

Yau, A. W., Peterson, W. K., and Shelley, E. G.: Quantitative parametrization of energetic ionospheric ion outflow, Washington DC American Geophysical Union Geophysical Monograph Series, 44, 211-217, https://doi.org/10.1029/GM044p0211, 1988.

Yermolaev, Y. I., Zelenyi, L. M., Kuznetsov, V. D., Chertok, I. M., Panasyuk, M. I., Myagkova, I. N., Zhitnik, I. A., Kuzin, S. V., Eselevich, V. G., Bogod, V. M., Arkhangelskaja, I. V., Arkhangelsky, A. I., and Kotov, Y. D.: Magnetic storm of November, 2004: Solar, interplanetary, and magnetospheric disturbances, J. Atmos. Sol.-Terr. Phy., 70, 334-341, https://doi.org/10.1016/j.jastp.2007.08.020, 2008.

Zhang, J., Richardson, I. G., Webb, D. F., Gopalswamy, N., Huttunen, E., Kasper, J. C., Nitta, N. V., Poomvises, W., Thompson, B. J., Wu, C.-C., Yashiro, S., and Zhukov, A. N.: Solar and interplanetary sources of major geomagnetic storms (Dst $\leq-100$ nT) during 1996-2005, J. Geophys. Res.-Space, 112, A10102, https://doi.org/10.1029/2007JA012321, 2007. 